\title{
MÁS DATOS HISTÓRICOS EN LAS INSCRIPCIONES DE PALENQUE *
}

por Alberto Ruz LHUILLIER

Centro de Estudios Mayas, UNAM.

Hasta hace algo más de diez años, los estudiosos de la cultura maya, al referirnos al contenido de las inscripciones jeroglíficas, nos limitábamos a repetir lo que nos habían enseñado nuestros maestros, Spinden, Morley, Thompson, principalmente, a saber, que ninguna información histórica revelaban tales inscripciones:

$\mathrm{Ni}$ un solo nombre de lugar o de persona ha sido definitivamente reconocido y traducido... no conocemos (entre los centenares de glifos de Copán y Palenque) los nombres reales de estas ciudades o siquiera sus símbolos. ${ }^{1}$ No encierran en manera alguna la glorificación de una persona..., no refieren historias de conquistas reales, ni registran los progresos de un imperio; ni elogian, ni exaltan, glorifican o engrandecen a nadie: son tan completamente impersonales y no-individualistas que hasta es posible que jamás se hayan grabado en ellas el nombre de algún hombre o de alguna mujer. ${ }^{2}$ Hasta donde llega nuestro conocimiento, los monumentos mayas con inscripciones - hasta hoy día se han encontrado algo más de 1000 de ellos con textos glíficos - tratan exclusivamente del paso del tiempo, de datos sobre la Luna y el planeta Venus, de cálculos calendáricos y de asuntos sobre los dioses y los rituales implícitos en estos temas. $^{3}$

- El autor agradece a las señoras Maricela Ayala y María Antonieta Ferreira del CEM la revisión de este artículo y sus observaciones respecto de $l_{a}$ interpretación de algunos jeroglíficos.

${ }^{1}$ Spinden, 1943: p. 126.

${ }^{2}$ Morley, 1936: pp. 181-182.

3 Thompson, 1959: p. 152. 
Tal creencia, basada sobre el conocimiento de los glifos de las fechas pero también sobre nuestra ignorancia casi absoluta de la significación de los signos no calendáricos, dio nacimiento a una supuesta obsesión de los mayas por el paso del tiempo. "Es igual que si erigiéramos nosotros un monumento al final de cada cinco o diez años y grabáramos en él la correspondiente fecha - domingo, 31 de diciembre de 1950; sábado 31 de diciembre de 1960; etc.- - juntamente con información sobre la edad de la luna y los dioses entonces regentes." 4

Para explicar este "interés absorbente" por el tiempo, se atribuyó a los mayas una "filosofía del tiempo", ${ }^{5}$ una "cronovisión del universo". ${ }^{8}$ Como si los mayas se hubieran dedicado a registrar en más de un millar de inscripciones, durante varios siglos, en centenares de sitios sólo el paso del tiempo, sólo el tiempo por el tiempo.

Ahora comprendemos que nuestras lucubraciones sobre el tema se debían a una premisa falsa tomando una parte por el todo, y no pudiendo descifrar más que las fechas registradas, dábamos a la totalidad de las inscripciones un contenido cronológico: todo era paso del tiempo y conceptos religiosos o ceremonias rituales asociados.

Esta situación comenzó a modificarse cuando hace 14 años un artículo de Berlin ${ }^{7}$ revelaba que entre los glifos mayas, existía uno "especial y exclusivo de cada ciudad". No podía el autor del trabajo precisar si se trataba del nombre del sitio, de una deidad tutelar o de una dinastía, por lo que prudentemente denominó "emblema" al signo. Presentó los glifos "emblemas" de varios importantes centros mayas: Tikal, Naranjo, Yaxchilán, Piedras Negras, Palenque, Copán, Quiriguá, Seibal, todos perfectamente caracterizados y constantes en cada localidad. En pocos casos, el "emblema" de una ciudad aparece en otra cercana, lo que sugiere una probable relación de dependencia de una hacia la otra.

Al año siguiente, el mismo investigador, después de analizar las inscripciones esculpidas sobre el sarcófago del Templo de las Inscripciones, en Palenque, llegó a la conclusión de que los individuos - hombres y mujeres - representados en los costados del sarcófago, debían ser personajes históricos, cada uno acompañado de un par de jeroglíficos. ${ }^{8}$ Varios de ellos aparecen repetidos dos veces y siempre con los mismos glifos. Cuando la persona es mujer - lleva entonces

\footnotetext{
Ibidem.

5 Ibidem.

- León-Portilla, 1968.

7 Berlin, 1958.

8 Berlin, 1959.
} 
capa y pelo largo- uno de sus glifos es conocido por corresponder a la joven diosa que simboliza el numeral 1 y acompaña a los personajes femeninos en monumentos esculpidos y pinturas murales (Bonampak). Algunos de los jeroglíficos asociados a estos personajes del sarcófago, se encuentran también en la faja que contiene glifos calendáricos, esculpida en el canto de la gran lápida sepulcral, probables referencias a dichos personajes, y asociados en dicha faja a fechas calendáricas mediante el glifo "quinconce" (cuatro puntos dispuestos como esquinas de un cuadrado, más otro punto al centro), cuyo significado se ignora (Berlin se preguntaba " ¿Nacimiento? ¿Casamiento? ¿Muerte? ¿Conquista? ¿Comienzo del reinado?, etcétera"). Independientemente del papel específico que estos personajes representen en el sarcófago, para Berlin, existieron realmente, fueron seres históricos.

El avance mayor en este nuevo camino del relato de hechos históricos y de la existencia en las inscripciones de nombres de hombres y mujeres que participaron en tales hechos, lo realizó Tatiana Proskouriakoff, historiadora de arte y arqueóloga de mucha sensibilidad y agudeza. En efecto, su estudio de los monumentos con inscripciones, en Piedras Negras, ${ }^{9}$ es algo más que una mera hipótesis. En la asociación de varias estelas, con sus respectivas fechas, la primera representa lo que la autora llamó motivo de la entronización (ascension motif), y su significación parece bastante obvia: en un nicho situado en la parte superior de la estela, un personaje está sentado; desde abajo llegan hacia el nicho huellas de pie. La subida al trono está plásticamente expresada. En cada serie de monumentos, existe además una fecha más antigua que la de la entronización, que la autora denomina "fecha inicial" y que aparece junto a un glifo que representa la cabeza de una rana o sapo, volteada hacia arriba (upended frog glyph). Esta fecha, por el número de años que la separa de la fecha de acceso al trono, muy bien puede corresponder al nacimiento del personaje, así como a su nombre calendárico. La fecha de entronización ("fecha inaugural" la llama Proskouriakoff) va ligada a un glifo que Thompson llamó del "dolor de muelas" por representar una cara amarrada por una venda colocada verticalmente. Todas las fechas asociadas a una misma serie de monumentos caen dentro de un lapso que no rebasa la duración de una vida humana. Cada una de estas series debe relatar los momentos más trascendentales del reinado de un gobernante de Piedras Negras.

9 Proskouriakoff, 1960. 
Sesenta años antes que Tatiana Proskouriakoff, Charles Bowditch había intuido algo semejante a lo que ella dedujo, de una investigación cuidadosa en numerosos monumentos. Refiriéndose a la Estela 1 de Yaxchilán, escribió a principios de siglo: ${ }^{10}$ "La Estela 1 podría mostrar también, primero, el nacimiento; segundo, el comienzo de la iniciación a la edad de 12 años y 135 días; tercero, el fin de la iniciación, a la edad de 12 años y 140 días; cuarto, el ascenso a jefe, a la edad de 32 años y 85 días, y el resto de la historia podría estar en los lados del monumento."

El mismo Morley, que con tanta seguridad negara el contenido histórico de las inscripciones mayas, había escrito, cuando apenas estaba iniciándose en el campo de la epigrafía maya: "...el autor cree, sin embargo, que fundamentalmente (las inscripciones) son históricas... y que la gran mayoría de estas fechas son las de acontecimientos contemporáneos, y como tales pertenecen al tema de la historia". ${ }^{11}$ Curiosamente, abandonó después este punto de vista, y quedó aceptado como dogma, entre los investigadores, que no debía buscarse historia en los monumentos mayas.

Pero volvamos a Tatiana Proskouriakoff, quien investigó en otros sitios la confirmación de lo que había descubierto en Piedras Negras. Su trabajo sobre las inscripciones de Yaxchilán, ${ }^{12}$ resultó aún más fructífero que el anterior, aunque la forma de levantar los monumentos en Yaxchilán y los acontecimientos en ellos relatados, difieren notablemente de los de Piedras Negras. Pudo aplicar algunas de las interpretaciones dadas a ciertos glifos de Piedras Negras: nacimiento, acceso al trono, entre ellos; pero identificó otros como el de captura de un prisionero y el del autor de ésta, siempre asociados a escenas bélicas y prisioneros con hombres armados, autosacrificios y sacrificios humanos. Relacionando entre sí el tema de las escenas, los personajes que participan, las fechas registradas, los jeroglíficos que suelen acompañar a ciertas acciones y los que identifican a los individuos, Proskouriakoff pudo trazar, a grandes rasgos, los hechos principales del reinado de algunos gobernantes de Yaxchilán: Escudo-Jaguar y sus descendientes; sus luchas y victorias contra otros jefes: Muerte o Abau, Cruz de Kan, Cráneo Enjoyado, identificados todos por sus glifos nominales.

Es así como su interpretación sugiere los nombres de los jefes, de sus predecesores y sucesores, de ancestros famosos, de señores enemigos,

10 Bowditch, 1901: p. 13.

11 Morley, 1915: p. 33.

12 Proskouriakoff, 1963 y 1964. 
de prisioneros y de quienes realizan la captura, de linajes, de posibles usurpadores extranjeros, de mujeres relacionadas con los jefes (madre, esposas); entre los eventos registrados estarían los más fundamentales, como nacimiento, acceso al trono, matrimonios, muerte de los señores; luchas contra enemigos extraños o entre los mismos señores para conquistar el poder; posibles arreglos para alianzas familiares (matrimonios) con otros jefes; captura de prisioneros y sus sacrificios; autosacrificios rituales; nombres de sitios quizá vasallos de Yaxchilán, etcétera. En síntesis, la mayor parte de los acontecimientos que la historia política de las dinastías universales acostumbran registrar.

Siguiendo el camino trazado por Proskouriakoff, David Kelley se interesó por descifrar el contenido histórico de los monumentos de Quiriguá. Aunque no logró reunir la cantidad y variedad de datos que proporcionó Yaxchilán, interesante información parece hallarse en las inscripciones de aquel centro. ${ }^{13}$ Propuso Kelley los nombres de cinco dirigentes sucesivos, cubriendo un lapso de 55 años. Estos nombres aparecen en frases cuyos elementos forman cláusulas que se repiten. Ciertos glifos indican, como lo comprobó Proskouriakoff en Piedras Negras y Yaxchilán, personajes femeninos; otros sugieren lazos de parentesco. Los nombres de algunos jefes se citan en varios monumentos de fechas distintas, mostrando la perduración de su recuerdo o fama.

Es importante el hecho de que los jeroglíficos marcan relaciones entre Quiriguá y Copán, cuya afinidad iconográfica (tema y estilo) es obvia. Según Kelley, el fundador de la dinastía de Quiriguá estaría emparentado con un jefe identificado de Copán, y uno o dos dirigentes de Copán comparten nombres y títulos con otros de Quiriguá. El nombre patronímico de los jefes de Quiriguá y sus familiares de Copán sería Caan (cielo).

En un trabajo reciente ${ }^{14}$ Berlin analiza la placa de los 96 glifos, de Palenque, y llega a conclusiones de gran importancia: entre otras, las de que cierta agrupación de glifos que se repite en la placa y en otros monumentos palencanos debe corresponder a nombres de personajes importantes — señores - que serían "actores" de la historia palencana, y que un determinado jeroglífico debe tener la significación de acceso a un cargo sacerdotal de alto rango.

A raíz del descubrimiento de la tumba en el Templo de las Inscripciones, en Palenque, dijimos con cierta reticencia:

13 Kelley, 1962.

14 Berlin, 1968. 
A reserva de que los especialistas discutan esas fechas (de la lápida sepulcral), comparándolas con otras inscripciones conocidas, se nos ocurre que una lápida sepulcral "lógicamente" debería llevar como inscripción un texto relacionado con el individuo cuyo sarcófago cubre, es decir las fechas de su nacimiento y muerte, así como la relación de sus hazañas si se trata de un importante personaje, como es seguramente el caso de referencia. Repitiéndose las ruedas calendáricas cada 52 años, es muy factible que las 13 registradas en la lápida se relacionen con los hechos fundamentales de la existencia del gran señor enterrado, por más que sería imposible entonces precisar las fechas en términos de tiempo absoluto, y por supuesto más imposible aún relacionarlas con acontecimientos reales. ${ }^{15}$

Nuestra reticencia se debía a que no se había puesto en duda todavía el dogma de la ausencia de información histórica en las inscripciones mayas.

Posteriormente, cuando redactamos hace 12 años la monografía del Templo de las Inscripciones, ${ }^{16}$ después de la publicación de los citados trabajos de Berlin y Proskouriakoff, en el capítulo Epigrafía, analizamos las fechas registradas sobre la lápida, desarrollando nuestra primera intuición, justificada ahora por las hipótesis de estos autores. Independientemente de los datos que presentamos en la referida monografía, damos aquí una interpretación más completa de las inscripciones esculpidas en el canto de la lápida funeraria, la que incluye por supuesto, con algunas modificaciones, las conclusiones a que llegamos entonces.

El primer punto a resolver era definir el comienzo de la inscripción, ya que ésta da la vuelta a la lápida, pasando de una cara a la otra, sin que nada específico marque el punto de partida. Como se sabe, la entrada a la tumba se halla en el extremo sur de la cripta, y es el lado sur de la lápida el único que está a la vista al situarse en el umbral. La importancia de este lado fue recalcada, pintándolo de rojo, mientras que los otros lados carecen de pintura, y que dos de ellos (este y oeste) difícilmente pueden verse debido al reducido espacio que queda entre la lápida y los muros. Es decir que lógicamente, por la posición del sarcófago en relación con la cripta y su entrada, la inscripción registrada sobre la lápida debe iniciarse en el lado sur, y siguiendo el orden de izquierda a derecha, que es el

\footnotetext{
15 Ruz, 1955: p. 94.

16 Ruz, 1973.
} 
único que puede seguirse en una serie horizontal de jeroglíficos mayas, se debe continuar por el lado este, pasar al norte y terminar con el oeste, hasta cerrarse el perímetro de la lápida. Para la lectura de esta inscripción, seguimos el orden indicado y dimos, en cada lado, una letra mayúscula del alfabeto a cada cartucho, el que puede consistir en un solo jeroglífico, o bien en un jeroglífico y un numeral, o en un glifo principal y uno o varios afijos, o en varios glifos principales con distintos afijos.

El siguiente punto a dilucidar era la posición de las fechas dentro del tiempo absoluto. Como se desprende del análisis de los elementos de que se compone la inscripción, no hay en ella ninguna fecha de Series Iniciales o de Cuenta Larga, sino sólo trece fechas de Ruedas Calendáricas, las que se repiten cada 52 años.

Varios factores pueden considerarse para intentar fijar estas fechas dentro de la Cuenta Larga: a) el periodo de florecimiento de Palenque, tal como se encuentra fechado por inscripciones en otros edificios, por el estilo arquitectónico y por la cerámica asociada a las construcciones; $b$ ) la presencia de algunas de las fechas de la lápida en otros monumentos palencanos, asociadas en estos últimos a fechas de Series Iniciales; c) la probable relación entre la inscripción sobre la lápida y el personaje enterrado en el sarcófago.

a) Las fechas consideradas como contemporáneas de los principales edificios palencanos (Sol, Cruz, Cruz Foliada, xvıIr, Palacio), caen dentro de los Katunes octavo a decimoquinto del Baktun noveno, es decir en cifras redondas entre 600 y 750 d.C. Estas construcciones se asemejan por su estilo al Templo de las Inscripciones y todas deben ser más o menos de la misma época. En cuanto a la cerámica asociada al Templo de las Inscripciones, descartando la que fue hallada en el relleno de su basamento (material anterior a la edificación), pertenece a las fases que Rands denominó Otulum, Murciélagos y Balunté, ${ }^{17}$ correspondientes al periodo Clásico Tardío y más concretamente a las fases Tepeu I y II en el Petén (600 a 800 d.C.).

Todos los datos coinciden por lo tanto en indicar, para el florecimiento de Palenque, los siglos vir y viII d.C., es decir el lapso comprendido aproximadamente entre las fechas mayas 9.8.0.0.0 y 9.18.0.0.0.

b) Las fechas de Series Iniciales asociadas en varios monumentos de Palenque a algunas de Ruedas Calendáricas registradas sobre la

${ }^{17}$ Rands, 1967: pp. 117-125. 
lápida sepulcral, fueron interpretadas por Spinden, ${ }^{18}$ Thompson ${ }^{19} \mathrm{y}$ Berlin, ${ }^{20}$ (sin divergencia importante) en la siguiente forma:
Para 8 AHAU 13 POP ....... 9.8.9.13.0 (en el Tablero Oeste del Templo de las Ins- cripciones y en la Es- calera de la Casa "C" del Palacio)

Para 6 ETZNAB 11 YAX ... 9.12.11.5.18 (en el Tablero Oeste del Templo de las Inscripciones)

Para 7 AHAU 3 KANKIN .... 9.7.0.0.0 (en el Tablero Este del Templo de las Inscripciones)

Para 1 AHAU $8 \mathrm{KAYAB}$.... 9.10.0.0.0 (en el Tablero Este del Templo de las Ins. cripciones).

c) El otro factor que juzgamos imprescindible tomar en cuenta fue el de la relación que debe existir entre las fechas registradas en la lápida y la vida del personaje enterrado en el sepulcro. Como ya dijimos, tales fechas son de Ruedas Calendáricas y se repiten cada 52 años. Dentro del tiempo que hemos asignado al florecimiento de Palenque, y considerando las citadas fechas como consecutivas y asociadas a la existencia del personaje, 4 series de fechas de Series Iniciales aparecen posibles, tomándose para cada serie la fecha más antigua y la fecha más tardía registradas, y aplicando para la equivalencia en nuestro calendario la correlación Goodman-Martínez-Thompson:
I - de 9.8.9.13.0
a 9.10 .10 .1 .6
(de 603 a 643 d.C.)
II — de 9.11.2.8.0
a 9.13 .2 .14 .6
(de 655 a 694 d.C.)
III — de 9.13.15.3.0
a 9.15 .15 .9 .6
IV — de 9.16.6.16.0
a 9.18 .8 .4 .6 .
(de 707 a 747 d.C.)
(de 759 a 798 d.C.)

Aunque las cuatro series caen dentro del periodo de florecimiento palencano (9.8.0.0.0 a 9.18.0.0.0) dos de ellas (III y IV) son posteriores a la fecha más tardía registrada en los tableros del templo (9.13.0.0.0), y consecuentemente a la edificación del conjunto arqui-

\footnotetext{
18 Spinden, 1924: pp. 196-206.

19 Thompson, 1932.

20 Berlin, 1951.
} 


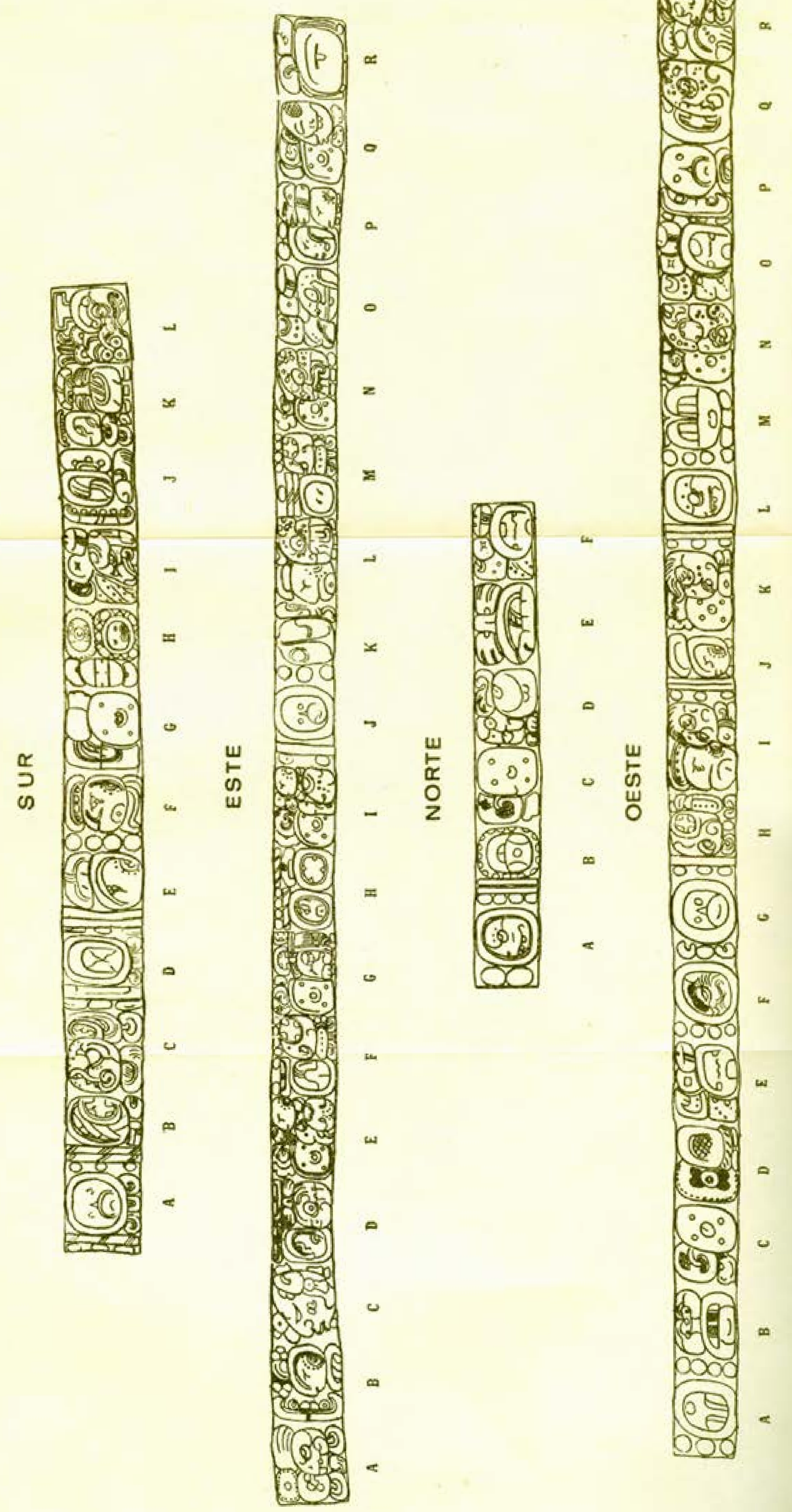


tectónico, tumba inclusa, por lo que creemos deben descartarse. Además, las fechas de Series Iniciales asociadas en estos tableros a varias de Ruedas Calendáricas de la lápida sepulcral, se encuentran comprendidas en las dos primeras series. Leyéndolas en el orden que hemos indicado anteriormente, y comenzado por el sur, tendríamos para las Ruedas Calendáricas las siguientes Series Iniciales:

\begin{tabular}{|c|c|c|c|c|}
\hline & & & Serie I & Serie II \\
\hline & 8 Abau & 13 Pop & 9.8.9.13.0* & 9.11 .2 .8 .0 \\
\hline & 6 Etznab & $11 Y a x$ & 9.9.18.10.18 & $9.12 .11 .5 .18 * *$ \\
\hline \multirow[t]{6}{*}{ ESTE } & 5 Caban & $5 M a c$ & 9.9.15.12.17 & 9.12 .8 .7 .17 \\
\hline & $7 \mathrm{Cib}$ & 4 Kayab & 9.9 .3 .13 .16 & 9.11 .16 .8 .16 \\
\hline & 9 Manik & 5 Yaxkin & 9.9.9.5.7 & 9.12.2.0.7 \\
\hline & 7 Abau & 3 Kankin & 9.9 .12 .13 .0 & 9.12 .5 .8 .0 \\
\hline & 11 Cbicchan & 3 Kayab & 9.10 .2 .0 .5 & 9.12 .14 .13 .5 \\
\hline & $2 E b$ & $0 \mathrm{Ceb}$ & 9.9 .11 .10 .12 & $9 \cdot 12.4 .5 .12$ \\
\hline NORTE & 2 Cimi & $14 \mathrm{Mol}$ & 9.8 .19 .4 .6 & 9.11 .11 .17 .6 \\
\hline \multirow[t]{6}{*}{ OESTE } & 3 Chuen & 4 Uayeb & 9.8.18.14.11 & 9.11 .11 .9 .11 \\
\hline & $4 O c$ & $13 Y a x$ & 9.8 .8 .3 .10 & 9.11 .0 .16 .10 \\
\hline & 1 Abau & $8 K a y a b$ & 9.10 .0 .0 .0 * & 9.12 .12 .13 .0 \\
\hline & $40 c$ & 8 Kayab & 9.9 .9 .15 .10 & 9.12 .2 .10 .10 \\
\hline & 1 Abau & $13 Y a x$ & 9.8 .18 .6 .0 & 9.11 .11 .1 .0 \\
\hline & $13 \mathrm{Cimi}$ & 4 Pax & 9.10 .10 .1 .6 & 9.13 .2 .14 .6 \\
\hline
\end{tabular}

Si se tomaran indistintamente fechas de una y otra de estas dos series, el intervalo entre la más antigua de la Serie I y la más tardía de la Serie II sería de 92 años. La distancia temporal entre la más antigua, también registrada en el templo (9.8.9.13.0) y la más tardía también registrada en uno de los tableros (9.12.11.5.18) sería de 81 años. En ambos casos, las fechas extremas rebasarían el probable promedio de vida de un antiguo maya, y duplicarían la edad atribuida al esqueleto por el estudio antropológico (40 a 50 años). Por el contrario, el intervalo de tiempo entre la fecha más antigua y la más reciente en cada serie es sólo por menos de tres meses inferior a 40 años. De ahí que pensamos que deben tomarse en cuenta sólo las fechas de Cuenta Larga de una de estas series. ¿Pero cuál escoger? Con la Serie I, dos fechas de la lápida (8 Abau 13 Pop y 1 Abau $8 \mathrm{Kayab}$ ) * se encuentran también en los tableros del templo, y una de ellas, además, en la escalera de la Casa "C" del Palacio. Con la Serie II, una fecha de la lápida (6 Etznab 11 Yax)** se halla también en uno de los tableros del templo y además sobre el Tablero 
del Palacio. Por otra parte, si, como pensamos, el personaje enterrado en la cripta es el mismo que ordenó la construcción de todo el conjunto arquitectónico (tumba, pirámide y templo), incluyendo las inscripciones esculpidas sobre los tableros del templo, es más probable que las fechas de la lápida funeraria estén asociadas a las más tardías de los tableros y no a las más antiguas. Las fechas de los tableros registran la sucesión de katunes, desde 9.4.0.0.0. hasta 9.13. 0.0.0, y probablemente hechos asociados a tales fechas, hechos ocw rridos ya cuando terminó la construcción del templo. Las fechas de nuestra Serie II abarcan justamente los últimos dos katunes registrados en los tableros del templo. Por ello, escogimos esta segunda serie.

Interpretación de la inscripción jeroglifica

\section{LADO SUR}

A-B: 8 Abau 13 Pop = fecha de nacimiento del personaje enterrado (655 d.C.) y nombre calendárico (Uaxac Abau), o más probablemente Wöxök Ajau en lengua chol que corresponde a la región de Palenque y que probablemente se hablaría en el sitio en tiempos prehispánicos.

C: Glifo de la rana virada considerado por Proskouriakoff, Berlin y Kelley como indicador del nacimiento (T.740.181).* La combinación A-B-C aparece en el Tablero Oeste del templo (E2-E3 F3), con el glifo de la rana volteada antes de la fecha 8 Abau 13 Pop. Combinación semejante pero con otra Rueda Calendárica (13 Caban $10 \mathrm{Ceb}$ ) está en el mismo tablero (K11-L11-K12).

D-E: 6 Etznab 11 Yax = probable fecha de acceso al trono, por ser la segunda registrada, y siguiendo el patrón hallado en otros sitios. El personaje tendría 28 años (683 d.C.). Esta fecha es la penúltima registrada en el último (oeste) tablero del templo, precediendo en 122 días a la última. Sugerimos que el tablero, ordenado por el personaje posteriormente enterrado en la cripta, registró hacia el final la fecha de la entronización y después la de la inauguración o consagración del templo.

* La designación de los glifos se hizo según el catálogo de Eric Thompson. 
F: Glifo "Cauac alado" (T.11:528:116) con numeral 4. ¿49 año (baab), 4 años completados (¿de que?) o variante del glifo T.644a que según Berlin podría indicar entronización?

G: ¿Adelante hacia... comienzo del reino? (Berlin sugiere que el quinconce, entre otros significados podría indicar el inicio de un reino) (T.679a.100:585a).

F-G: La combinación de los dos glifos anteriores (Cauac y quinconce) con ciertas variantes (sin numeral ni "barba" o "ala" el Cauac; con distinto prefijo el quinconce) aparece en el Tablero Este del templo (A12-B12).

H: El glifo T.184.624, con T.583 y T.533 infijado como superfijo, aparece en el Tablero del Palacio $\left(\mathrm{C} 12\right.$ y P19) ${ }^{21}$ y en el Tablero de los Esclavos (B1). ${ }^{22}$ T.624 es idéntico al objeto que en ambos tableros ofrece una mujer al personaje central. Este objeto debe representar un escudo, símbolo de alta jerarquía. T.184.624 se conoce de la Lápida de los 96 glifos $(\mathrm{Cl} ; \mathrm{K} 7)^{23}$

I: Variante del Glifo--Emblema de Palenque, (T.24:138.168: 747) con cabeza de zopilote (en vez de cráneo) y superfijo Ben-Ich, precedido de un afijo que por llevar líneas de puntos debe pertenecer al grupo de afijos acuáticos que acompañan a los glifos-emblemas.

H-I: La combinación de los 2 glifos anteriores se repite con variantes en el Tablero Este del templo (R11-Q12), en el Tablero Central (C4-D4; E8-E9; G3-G4), y en el Tablero Oeste (I5-I6; O2-P2; T12). La cabeza del zopilote vendría a sustituir en el glifo-emblema palencano al cráneo o al signo convencional de "hueso" (T.570). Combinación semejante aparece también en la Lápida de los 96 glifos (D6-C7; F4-F5; G4-H4), mientras que nuestro cartucho $\mathrm{H}$ se repite también en la misma lápida $(\mathrm{C} 1 ; \mathrm{K} 7)$. La cláusula $\mathrm{H}-\mathrm{I}$ de la lápida sepulcral puede ser equivalente $o$ acercarse bastante a la que Berlin menciona para la Lápida de los 96 glifos (T.74.184.624) seguida o no del glifo-emblema, cuyo significado sería el nombre de un señor palencano. Si el elemento significativo susceptible de variar es, en la tapa del sarcófago, el signo "escudo" (T.624), existe la posibilidad de que el personaje enterrado se haya conocido como 8 Abau-escudo. El escudo semejante, que ofre-

\footnotetext{
${ }^{21}$ Ruz, 1952-a: fig. 8.

${ }^{22}$ Ruz, 1952-b: fig. 12.

${ }^{23}$ Berlin, 1968.
} 
cen mujeres al personaje central en los tableros del Palacio y de los Esclavos, podría haber estado asociado, todavía en tiempos posteriores, al nombre o al linaje de 8 Abaut.

$\mathrm{J}$ : El elemento principal, especie de swastika (T.573a.21:88?) ha sido interpretado por Thompson como equivalente a la palabra maya bel que significa cambio, sucesión o sucesor, ${ }^{24}$ sentido que completaría lo que debe estar expresado en este lado de la lápida: nacimiento y entronización del personaje enterrado en el sarcófago.

$\mathrm{K}$ : Combinación de glifos en que Caban (T.11.526:88:246) y Mac (T.1:74:556:255) no tienen significado calendárico. Corresponde a algo o a alguien ligado con el personaje enterrado; quizás sea el nombre del personaje a quien 8 Abau sucedió, hecho anunciado por el glifo anterior $(\mathrm{J})$.

L: Combinación de glifos (T.340:315:824 y T.48:764) cuyo sentido no interpretamos.

\section{LADO ESTE}

A: Combinación de glifos que no interpretamos (T.79:21.1 047a: 125).

B: Combinación de glifos que no interpretamos (T.1.174:530: 24) en que el Cauac va precedido del prefijo $U(\mathrm{Su})$.

C: La cabeza de la joven diosa (T.1 000a o 1001) que suele referirse a un personaje femenino en las inscripciones, asociada aquí a los glifos anteriores que no identificamos, quizás designe a la esposa de $8 \mathrm{Abau}$, cuyo matrimonio podría haberse efectuado en la fecha expresada en los glifos inmediatamente posteriores.

D: 5 Caban $5 M a c=$ fecha en que 8 Abau tendría 25 años, posible fecha de su matrimonio ( 680 d.C.).

E: Nuevamente aparece la combinación quinconce (T.100:585a) y Cauac (ahora como superfijo de un glifo Uinal) que vimos en el lado sur (F-G) y que se encuentra también en el Tablero Este del templo (A12-B12). La misma combinación (T.228.528:238.244:522) se repite en la posición I del lado este de la lápida funeraria. Debe referirse a un personaje ligado a la vida de 8 Abau.

${ }^{24}$ Thompson, 1950: p. 161. 
F: 7 Cib 4 Kayab $=$ fecha en que el personaje 8 Abau tendría 14 años (669 d.C.).

G: El quinconce (T.100:585a) está asociado aquí con el glifo nominal "dolor de muela" (T.281.23:684b:142) del tercer personaje (contando de izquierda a derecha) en el lado oeste del sarcófago. El quinconce constituye el pectoral de este individuo, y lo usa también el individuo representado en lado norte (2) y en el lado sur (1) del sarcófago.

Es de hacerse notar que los personajes representados en los lados del sarcófago llevan como pectorales, sea el quinconce, sea el signo $i k$. Todas las representaciones femeninas usan el pectoral ik.

La referencia en la lápida a un personaje representado en el sarcófago, ya apuntada por Berlin, ${ }^{25}$ puede estar asociada a la fecha que precede.

H: 9 Manik 5 Yaxkin $=$ fecha en que 8 Abau tendría 19 años (674 d.C.).

I: Combinación de glifos idéntica a $\mathrm{E}$, indicando algo que ocurriría en la fecha que precede (T.100:585a y T.228.528:238. 244:522).

J-K: 7 Ahau 3 Kankin $=$ fecha en que 8 Abau tendría 22 años (677 d.C.).

L: Asociación Cauac-Jaguar (T.261:528 y T.751:142). La cabeza del jaguar ¿estará usada en un sentido de rango jerárquico? ¿o será una referencia a un linaje determinado? Recordemos el linaje reinante en Yaxchilán.

M: 11 Chicchan 3 Kayab (registrado erróneamente 4 Kayab) = fecha en que 8 Abau tendría 32 años.

$\mathrm{N}$ : El quinconce (T.100:585-a) aparece aquí asociado a la cabeza de jaguar (T.751:142). La cercanía de la misma cabeza (con el Cauac) en $\mathrm{L}$, sugiere una reiteración de un mismo hecho, título o linaje.

O: Probable variante del glifo-emblema de Palenque (P-la). El elemento principal es un cráneo; con los superfijos Ben-Ich (T.168:1047a) y los prefijos, con puntos en líneas oblicuas (T.138) se repite en el lado oeste de la lápida $(\mathrm{E}, \mathrm{O})$. La asociación cabeza de jaguar-glifo-emblema se encuentra en el tablero Este del templo (K1-L1).

P: $2 E b O C e b=$ fecha en que 8 Abau tendría 21 años (676 d.C.).

${ }^{25}$ Berlin, 1959: p. 6. 
Q: El quinconce (T.100:585a) está asociado aquí con la cara de la joven diosa (T.1000) que debe actuar como prefijo femenino $i x$.

$\mathrm{R}$ : Glifo Ik (T.351?:503)

Q-R: La combinación Q-R nos proporciona el jeroglífico del personaje femenino representado en el sarcófago (Este 3 y Oeste 2) como lo ha hecho notar Berlin, ${ }^{26}$ relacionando el compuesto glífico $i x-i k$ con el nombre $i x i k a l=$ señora principal, dado por el diccionario de Motul.

O-R: La combinación del glifo-emblema $(\mathrm{O})$ con los glifos femeninos $(\mathrm{Qb}-\mathrm{R})$, aunque en orden invertido, se encuentra en el Tablero Este del templo (L4-K5 y L8-K9). ${ }^{27}$ Esta referencia a un personaje femenino debe estar ligada a la fecha anterior, cuando tendría 8 Abau 21 años.

\section{LADO NORTE}

A-B: 2 Cimi $14 \mathrm{Mol}=$ fecha en que 8 Abau tendría 9 años.

C: La combinación T.100.585a, en que el quinconce es el elemento principal se repite idéntica en el lado oeste de la lápida (C), y la cláusula en que aparece en ambos lados es bastante semejante, comenzando por dicho conjunto y terminando por el glifo-emblema, aunque los glifos intermedios son distintos.

D-F: La cláusula D-E-F, en que D es la cabeza de la tortuga ( $T$. 743.198:506), E (Mac) (T.74:565a) no tiene valor cronológico, ya que carece de numeral y $\mathrm{F}$ es el glifo-emblema palencano (P-1b), existe en forma idéntica en el Tablero Este del templo (L11-K12-L12), y en forma algo parecida en otra posición (N4-M5-N5).

La combinación C-F (quinconce-glifo-emblema) se parece a una del Tablero Oeste del templo (I5-I6), y la combinación E-F (Mac-glifo emblema) está sugerida en el último cartucho del Tablero Oeste (T12) eliminando el primer glifo.

\section{LADO OESTE}

A-B: 3 Cbuen 4 Uayeb $=$ fecha en que 8 Abau tendría 9 años (155 días menos que en la fecha anterior).

26 Ibidem.

${ }^{27}$ Ibidem. 
C: Combinación T.100.585a idéntica a la que citamos en el lado norte (C).

D: La combinación de glifos T.583.602 parece relacionarse con el glifo T.624 que, en el análisis que hace Berlin de la lápida de los 96 glifos ${ }^{28}$ correspondería al nombre de un señor palencano. Los elementos de D aparecen en el Tablero Oeste del templo (A3; F2).

C-D: Los segundos glifos de ambos cartuchos (Cb-Db) constituyen los elementos principales de los glifos nominales del primer personaje (izquierda) en el lado oeste del sarcófago, como lo hizo ver Berlin. ${ }^{29}$

E: Glifo-emblema palencano (P-1b, de Berlin) ${ }^{30}$

D-E: La combinación de estos glifos es bastante o muy parecida en los tableros del templo (Este: R11-Q12; S12-T12. Central: C4-D4; E8-E9; G3-G4. Oeste: O2-P2; T12). Podría relacionarse con la combinación T.74.184.624-emblema, de la lápida de los 96 glifos, aunque en ésta el glifo-emblema puede faltar (B3-B4; C1; K7)..$^{31}$

F-G: 4 Oc 1 Abau (hubo un error por parte del escultor o del sacerdote que dirigió la inscripción, ya que pusieron dos días consecutivos que no integran ninguna fecha de Rueda Calendárica). Los glifos de los meses correspondientes vienen después en $\mathrm{H}$ y $\mathrm{J}$, y su combinación con los glifos de días permiten las siguientes alternativas:

F-H: $4 O c 8 \mathrm{Kay} a b=$ fecha en que 8 Abau tendría 20 años.*

F-J: 4 Oc 13 Yax = fecha en que aún no nacería 8 Abau.**

G-H: 1 Abau 8 Kayab = fecha en que 8 Abau tendría 30 años.**

G-J: 1 Abau 13 Yax = fecha en que 8 Abau tendría 8 años.*

(Las fechas compatibles en las inscripciones de la lápida podrían ser alternativamente las marcadas por un asterisco, o bien las que llevan dos, pero no una con un asterisco con otra de dos.)

I: Pensando en términos de una inscripción exclusivamente cronológica, el conjunto "Cauac-guacamaya" (T.11:528.744a:58) podría interpretarse como "asiento" (final) de Kayab (mes de la fecha anterior), o final de algún periodo, del katun, por ejemplo, en caso de considerar la Rueda Calendárica 1 Abau

${ }^{28}$ Berlin, 1968: p. 140.

${ }^{29}$ Berlin, 1959: p. 6.

so Berlin, 1958: fig. 28-3.

81 Berlin, 1968: p. 140. 
8 Kayab $=9 \cdot 10.0 .0 .0$. Sin embargo descartamos esta fecha, como se indicó al discutirse las Ruedas Calendáricas, y tratamos de interpretar la inscripción con enfoque de registro histórico. En realidad, es factible que el primero de los dos glifos " $H$ " no sea el T.528, sino el T.644a al que Berlin atribuye el posible sentido de entronización. ${ }^{32}$ El glifo "guacamaya" acompaña en los relieves del sarcófago al personaje femenino representado en el lado norte (1) y sur (2), con el mismo afijo zac (blanco) asociado al glifo en la inscripción que intentamos interpretar. Es posible que se trate de una referencia a una mujer de nombre "guacamaya blanca" (¿ix-zac-moo?) ligada a la vida de 8 Abau cuando tenía 20 o 30 años, según la lectura que se escoja entre las fechas de Ruedas Calendáricas erróneamente registradas.

K: El mismo glifo "guacamaya blanca" (T.744a:58) está ahora asociado al quinconce (T.100:585a). No sabemos si se trata del mismo personaje femenino acabado de mencionar y que Berlin considera ser el mismo en el sarcófago ( $\mathrm{N}-1, \mathrm{~S}-2)$ que en esta insćripción, o si se trata de un linaje en que la guacamaya blanca sería el simbolo distintivo o el nombre. Es de observarse que la figura de mujer esculpida en el sarcófago acompañada de tal glifo, lleva un yelmo caracterizado por el pico, la cresta y el ojo de la guacamaya. El glifo "guacamaya blanca" aparece también en el Tablero Oeste del templo (J6-K5).

L-M: 13 Cimi 4 Pax = última fecha registrada en la lápida, la más tardía de todas y que suponemos ser la de la muerte de 8 Abaut a los 40 años, misma edad que la mínima atribuida al esqueleto en los estudios antropológicos.

$\mathrm{N}$ : El quinconce (T.100:585a) está asociado aquí como prefijo a una cabeza de animal híbrido "guacamaya-jaguar", en que del ave sería el pico encorvado, pero cuya oreja y cuya piel manchada sería del felino (mezcla de T.744 y T.751). El ojo está ocupado por una cruz Kan. Ya Berlin ${ }^{33}$ había hecho notar la correspondencia entre el glifo $\mathrm{N}-\mathrm{b}$ de la lápida y el que acompaña al personaje representado en los relieves del sarcófago (Norte 2, Sur 1). Añadiremos que este personaje lleva yelmo de cabeza de guacamaya y pectoral de quinconce,

32 Berlin, 1968: p. 144.

33 Berlin, 1959: p. 6. 
lo que lo identifica aún con más razón con el aludido en la inscripción jeroglífica de la lápida. ¿Implica la cabeza híbrida la fusión de dos linajes "jaguar" y "guacamaya"? Recordaremos que en el lado este de la lápida, entre una fecha de Rueda Calendárica y el glifo-emblema de Palenque ( $\mathrm{M}-\mathrm{N}-\mathrm{O}$ ), aparece repetida la cabeza del jaguar, una de las veces precedida del afijo quinconce. Aquí tenemos una cláusula semejante: Rueda Calendárica-cabeza "jaguar-guacamaya" —glifo emblema palencano (L-M-N-O). Incluso la posición de esta cláusula es la misma en ambos lados de la lápida. Pensamos que el quinconce como pectoral debe simbolizar un rango jerárquico, y su asociación con una cabeza de animal - jaguar, guacamaya, jaguar-guacamaya - definiría el rango dentro de un linaje determinado.

O: Glifo-emblema de palenque ( $\mathrm{P}-1 \mathrm{~b}$, de Berlin), ${ }^{34}$ semejante a su representación en posición " $E$ " del mismo lado de la lápida. La combinación "cabeza de animal-glifo emblema" (N-O) aparece también en el Tablero Este del templo (K1L1), en que la cabeza es de jaguar.

P: La asociación glífica T.1.533.24 sugiere fuertemente la interpretación fonética $U$ abau(l)il "su señorío, su reino".

Q: Nuevamente la cabeza híbrida "guacamaya-jaguar", en que el pico y el ojo son de la guacamaya, la oreja y la piel de jaguar. El glifo va precedido del prefijo cruz Kan (T.281) que en la posición " $N$ " se encuentra en el ojo del animal. La repetición, a poca distancia, de estas cabezas nos recuerda la reiteración que mencionamos para el lado este de la lápida ( $\mathrm{L}$ y $\mathrm{N}$ ).

R: El primer glifo es la variante de "concha" (T.11.I:606a) al que Thompson atribuye el significado de completamiento (final) de periodo. ${ }^{35}$ Siendo el último glifo de la inscripción, que suponemos asociado a la muerte de $8 \mathrm{Abau}$, la alusión (T. $1000: 128$ ?) a un personaje femenino ¿podría sugerir una regencia femenina a causa de la minoría de edad del heredero de 8 Abau?

Q-R: La asociación "cabeza de animal (guacamaya-jaguar)-figura femenina" está también sugerida en el Tablero Este del templo (L4-M4) en que la cabeza es de guacamaya. 


\section{Sintesis}

Resumiendo los datos que creemos haber interpretado en la inscripción jeroglífica de la lápida sepulcral, tedríamos en forma hipotética, por supuesto, la siguiente información.

\section{LADO SUR}

(A-B-C) El día 8 Abau 13 Pop (9.11.2.8.0 = 13 de marzo de 655 d.C.) nació el heredero al trono de Palenque, que recibió su nombre calendárico de 8 Abau, probablemente Wöxök Ajau en lengua chol que sería la que se hablaba en la región, como hasta la fecha.

(D-E) Fue designado balach winic a los 28 años, en la fecha 6 Etznab 11 Yax (9.12.11.5.18 = 31 de agosto de 683 d.C.), que también se registró en la última columna (T.5) del Tablero Oeste del templo.

(F-G) Cuatro años después (?) recibió el título jerárquico, cargo - distinción que simbolizaba el pectoral de quinconce que llevan varios personajes - antepasados o familiares vivos - representados en los relieves del sarcófago.

(H) Recibe también el altísimo título simbolizado por el escudo y que en los tableros del Palacio y de los Esclavos una mujer presenta al personaje central. Es factible que "escudo" haya pasado a ser parte de su nombre ("sobrenombre" llamó Caso al elemento distintivo que acompaña al nombre calendárico de los señores mixtecos).

(I) Se precisa que estos títulos o distinciones se relacionan con Palenque.

$(\mathrm{J}-\mathrm{K})$ Es posible que haya sucedido en el trono a un señor cuyo nombre se representara con los glifos principales Caban y Mac y varios afijos.

\section{LADO ESTE}

(C-D) En la fecha 5 Caban 5 Mac (9.12.8.7.17 = 24 de octubre de 680 d.C.) se casó 8 Ahau, a los 25 años, siendo quizá el nombre de la mujer expresado en los glifos anteriores (A-B)

(E) Posible referencia a un personaje cuyo título o cargo se simbolizaría por el pectoral del quinconce y cuyo nombre se represen- 
taría por varios elementos, entre los cuales se distinguen el Cauac, el Uinal y la cabeza de la guacamaya. ¿Podría ser alusión al linaje de la esposa de 8 Abau?

(F-G) Referencia a un personaje - probable familiar de 8 Abauque aparece representado en el lado oeste del sarcófago (3), según lo identificó Berlin por su jeroglífico. ${ }^{36}$ Este individuo poseía el título que simboliza el quinconce y su relación con la vida de 8 Abau ocurre cuando éste tenía 14 años, en una fecha 7 Cib 4 Kayab (9. 11.16.8.16 = 14 de enero de 669). ¿Ocuparía el trono debido a la minoría de edad de 8 Abau?

(H-I) Referencia al mismo personaje mencionado anteriormente (E), con el título asociado al quinconce, y cuyo nombre comprende los elementos Cauac, Uinal y cabeza de guacamaya. Aquí va asociado a la fecha 9 Manik 5 Yaxkin, cuando 8 Abau tendría 19 años (9. 12.2.0.7 = 28 de junio de 674). Posible alusión a su iniciación como sacerdote.

(J-K-L) Cuando 8 Abau tenía 22 años, en la fecha 7 Abau 3 Kankin (9.12.5.8.0 = 12 de noviembre de 677), ¿recibiría una distinción título o cargo que simbolizaría la cabeza del jaguar? o ¿algo relacionado con un linaje o personaje "jaguar" ocurriría en Palenque?

Hacemos notar que el personaje central en el lado este del sarcófago lleva una cabeza de jaguar en su tocado.

(M-N) A los 32 años, en la fecha 11 Cbicchan 3 Kayab (9.12. $14.13 .5=9$ de enero de 687 ), se repite lo relativo al personaje o linaje "jaguar" registrado antes. Recordaremos aquí la presencia de un linaje "jaguar" en Yaxchilán. ${ }^{37}$

(O) Se precisa la asociación entre el personaje o linaje "jaguar" y Palenque.

(P-Q-R) En la fecha 2 Eb O Ceh (9.12.4.5.12 = 30 de septiembre de 676), cuando 8 Abau tenía 21 años, perece registrarse una referencia al personaje femenino representado en el sarcófago (Este 3 y Oeste 2), sin que podamos establecer el carácter de la relación entre ambos.

\section{LADO NORTE}

(A-F) Referencia quizás a un señor palencano, cuyo título o rango estaría expresado en $\mathrm{C}$ por el quinconce, y en cuyo nombre entrarían

36 Berlin, 1959: p. 6.

37 Proskouriakoff, 1964: pp. 177-200. 
los elementos "tortuga" (ac) y Mac, relacionado con 8 Abau cuando éste tenía 9 años, en una fecha 2 Cimi $14 \mathrm{Mol}$ (9.11.11.17.6 = 29 de julio de 664). La misma cláusula y otras semejantes se repiten varias veces en los tableros del templo, terminando siempre por el glifo-emblema de Palenque.

\section{LADO OESTE}

(A-E) Una cláusula semejante a la anterior (fecha de Rueda Calendárica-T.100:585a-par de glifos variables-glifo emblema palencano) se repite en el lado oeste, asociada ahora a una fecha 3 Cbuen 4 Uayeb en que 8 Abau estaba por cumplir 9 años (9.11.11.9.11 $=25$ de febrero de 664). Puede tratarse, como en el caso inmediato anterior, de un señor palencano emparentado con 8 Abau, y que está representado en un lado del sarcófago (Oeste 1 ).

$(\mathrm{F}-\mathrm{H}, \mathrm{J})$ Dijimos anteriormente que el error cometido al registrarse dos fechas de Rueda Calendárica consecutivas, permitía una doble interpretáción. Para decidirnos por una de ellas, descartamos la que inicialmente habíamos escogido ( $4 \mathrm{Oc} 13 \mathrm{Yax} ; 1$ Abau $8 \mathrm{Ka}$ $y a b)$, pese a que la segunda fecha se encuentra en los tableros del templo, por que implicaba una fecha en que aún no nacía $8 \mathrm{Abeu}$. Consideramos por lo tanto la otra posibilidad: 4 Oc 8 Kayab (9.12. $2.10 .10=17$ de enero de 675) y 1 Abau 13 Yax (9.11.11.1.0 $=7$ de septiembre de 663), cuyas fechas caen dentro del tiempo de existencia de 8 Abour.

$(\mathrm{F}, \mathrm{H}, \mathrm{I})$ Para una fecha 4 Oc 8 Kayab $(9.12 .2 .10 .10=17$ de enero de 675), en que 8 Abau tendría más o menos 20 años, se registró al parecer el nombre de un personaje femenino $i(i x)$ zacmoo? (guacamaya blanca) representado en los relieves del sarcófago (Norte 1, Sur 2), cuya relación con 8 Abau ignoramos.

$(\mathrm{G}, \mathrm{J}, \mathrm{K})$ En una forma semejante, para la fecha 1 Abau $13 \mathrm{Yax}$ (9.11.11.1.0 = 7 de septiembre de 663), cuando 8 Ahau tendría 8 años, se repite la referencia al personaje femenino "guacamaya blanca", asociado ahora al quinconce, posible título nobiliario o rango jerárquico, y al parecer la misma mujer que figura en los lados norte y sur del sarcófago, y cuyo glifo también se encuentra en uno de los tableros del templo.

(L-M) Por ser la última fecha registrada, 13 Cimi 4 Pax (9.13. 2.14.6 = 19 de diciembre de 694), la más tardía de toda la inscripción, y estar separada de la primera y más antigua en más o menos 
40 años (39 años, 9 meses y una semana), edad que aproximadamente los antropólogos atribuyeron a los restos óseos, suponemos que tal fecha ha de ser la de la muerte de 8 Abau.

(N-R) Es de suponerse que el final de la inscripción se registró inmediatamente después de la muerte de $8 \mathrm{Abau}$, en los días que siguieron y mientras se preparaban las ceremonias fúnebres que terminarían con su inhumación y la clausura de la cripta. La repetición, asociada al glifo-emblema de Palenque $(\mathrm{O})$ de la cabeza de un animal híbrido "jaguar-guacamaya", nos sugiere la posibilidad de una regencia, o gobierno provisional, en que los linajes "jaguar" y "guacamaya", aludidos en varios glifos de la inscripción, estuviesen representados, unidos como sugiere el glifo. El glifo T.1.533:24, con el sentido de U-abau-l-il, "su reino", después del glifo-emblema de $\mathrm{Pa}$ lenque, asociado al penúltimo glifo $(R, a)$ que según Thompson ${ }^{38}$ tendría la significación de "completamiento de periodo", evocaría el fin del reino de $8 \mathrm{Abau}$. El último glifo al parecer la cabeza femenina (variante de T. 1000 ) podría aludir a una mujer, familiar cercana de $8 A h a u$, que tuviera la jefatura de la regencia sugerida.

\section{Conclusiones}

Comprendemos todo lo que nuestra interpretación tiene de hipotética pero, aunque errónea en parte, debe acercarse al carácter y contenido de la inscripción. Nos parece imposible aceptar que un personaje de la importancia del que fue enterrado en el mausoleo más monumental y espectacular de la América precolombina hasta ahora descubierto, con lo que implica del altísimo concepto en que él mismo se tenía, no hubiera hecho registrar sobre su tumba los datos que consideró de interés sobre sí mismo y sobre algunos eventos de su reinado. Con esta premisa, es lógico pensar que figuren en la inscripción la mención de su nacimiento, acceso al trono, matrimonio(s), alianzas, vasallaje de algunos señores de la región, referencias a familiares ilustres - antecesores y contemporáneos-, linajes emparentados. La falta de manifestaciones de hechos bélicos en el conjunto arquitectónico (tumba, pirámide, templo) y de jeroglíficos asociados a violencia, como el glifo "captura" de Yaxchilán, sugiere que no se registró guerra o conquista alguna en la inscripción de la tumba.

\footnotetext{
38 Thompson, 1962: p. 230.
} 
Después de las interpretaciones con enfoque histórico presentadas por Berlin, Proskouriakoff y Kelley, después de que el mismo Thompson, en su libro más reciente, ${ }^{39}$ reconoce el probable contenido histórico de las inscripciones mayas, creemos que nuestra tentativa de sacar una información histórica de las inscripciones registradas en la lápida sepulcral de la tumba, en el Templo de las Inscripciones de Palenque, está debidamente justificada, aunque, repetimos, deja muchos puntos en la oscuridad y debe contener errores.

Consideramos que las fechas que hemos atribuido a las Ruedas Calendáricas se ajustan a nuestra premisa de que se relacionan con la vida del personaje, y que son probablemente las únicas que en este sentido funcionan debidamente. Podría arguiirse que, aunque todas las fechas quedan dentro del marco de su vida, no están ordenadas en secuencia progresiva, y que varias veces retroceden, cuando lo lógico sería que sin excepción se sucedieran siempre desde atrás hacia adelante. Sin embargo, si analizamos la mayor parte de las inscripciones mayas de cierta extensión, es frecuente que después de una fecha tardía, ocurra otra más temprana. Por ejemplo, para sólo mencionar a Palenque, en los Tableros del Templo de las Inscripciones, según la lectura de Spinden, Thompson y Berlin, ${ }^{40}$ el retroceso cronológico se presenta varias veces. También aparece en el Tablero del Palacio. ${ }^{41}$

La explicación puede ser que la inscripción no es el simple desarrollo esquematizado de la vida del personaje, que no relata sólo los hechos de su propia existencia -nacimiento, entronización, muerte- en su secuencia natural, sino que además hay referencias a otras personas, casi todas representadas en los relieves laterales del sarcófago, las que por alguna razón estuvieron ligadas a la historia del personaje enterrado, en alguna época de su existencia.

Resultaría muy difícil creer que los mayas no hubieran tenido preocupación por dejar constancia de su historia, como la tuvieron otros pueblos mesoamericanos como los mixtecas, aztecas y otros. Además la información histórica que nos han legado las crónicas mayas (yucatecas), quichés y cakchiqueles demuestra que en el momento de la llegada de los españoles, esa preocupación histórica estaba vigente, y presupone que los datos transcritos en esas crónicas venían siendo registrados (en códices, estelas, dinteles, etcétera) desde seguramente hacía muchos siglos.

39 Thompson, 1970: pp. 41-42.

40 Spinden (1924), Thompson (1932), Berlin (1951).

41 Thompson, 1952. 
Por más que las tentativas realizadas hasta ahora en la interpretación histórica de las inscripciones mayas adolecen sin duda de fallas y puntos oscuros, constituyen sin embargo un importante paso hacia adelante en la historia del desciframiento de tales inscripciones.

Si con los avances en la interpretación histórica de los textos jeroglíficos mayas, los conceptos elaborados por distinguidos investigadores sobre la filosofía del tiempo (quien escribe habló alguna vez de metafísica del tiempo) y la cronovisión de los antiguos mayas, pierden su validez - parcial o totalmente- y le restan a la cultura maya lo que, según se pensaba, constituía una peculiaridad de pensamiento única en el mundo, en compensación nos acercamos un poco más a su realidad histórica y la situamos con mayor veracidad entre las demás grandes culturas de la antigüedad.

\section{BIBLIOGRAFIA}

BERLIN, HEINRICH

1951 "La Inscripción del Templo de las Leyes en Palenque", Anales de la Sociedad de Geografía e Historia de Guatemala, t. XXV, núms. 1 y 2, Guatemala, pp. 120-128.

1958 "El Glifo-Emblema en las Inscripciones Mayas", Journal de la Société des Américanistes, n. s., tomo XLVII, Paris, pp. 11-119.

1959 Glifos Nominales en el Sarcófago de Palenque. Humanidades, vol. II, núm. 10. Depto. de Historia, Universidad de San Carlos, Guatemala.

1968 "The Tablet of the 96 Glyphs at Palenque, Chiapas, Mexico", Middle American Research Institute, publ. 26, New Orleans, pp. $135-149$.

BOWDITCH, CHARLES

1901 Notes on the Report of Teobert Maler. Memoirs of the Peabody Museum, Harvard University, vol. II, núm. 1, Edición privada, Cambridge.

KELLEY, DAVID

1962 "Glyphic Evidence for a Dynastic Sequence at Quiriguá, Guatemala", American Antiquity, vol. 27, núm. 3, Salt Lake City, pp. 323-335.

LEÓN PORTILLA, Miguel

1968 Tiempo y realidad en el pensamiento maya. Instituto de Investigaciones Históricas, UNAM, México, D. F.

MAUDSLAY, ALFRED

1889. "Archaeology", Biologia Centrali-Americana, vol. IV, London, 1902 Pl. 60-62. 
MORLEY, SYLVANUS

1915 An Introduction to the Study of the Maya Hieroglyphs. Bureau of American Ethnology, Smithsonian Institution, Bulletin 57, Washington, D. C.

1936 Guía de las Ruinas de Quiriguá. Institución Carnegie de Washington, D. C.

PRoskourIakoff, TATIANA

1960 Historical implications of a pattern of dates at Piedras Negras, Guatemala. American Antiqwity, vol. 25, núm. 4, Salt Lake City.

1963 "Historical Data in the Inscriptions of Yaxchilan, Part 1", Estudios de Cultura Maya, UNAM, vol. III, México, D. F., pp. 149-167.

1964 "Historical Data on the Inscriptions of Yaxchilan, Part II", Estudios de Cultura Maya, UNAM, vol. IV, México, D. F., pp. 177-200.

RANDS, ROBERT

1967 "Cerámica de la región de Palenque, México", Estudios de Cultura Maya, UNAM, vol. VI, México, D. F., pp. 111-147.

RUZ LHUILLIER; ALBERTO

1952a "Exploraciones en Palenque: 1949", Anales del Instituto Nacional de Antropología e Historia, tomo IV, núm. 32, México, D. F., pp. 49-60.

1952b "Exploraciones en Palenque: 1950", Anales del Instituto Nacional de Antropología e Historia, tomo V, núm. 33, México, D. F., pp. $25-45$.

1955 "Exploraciones en Palenque: 1955", Anales del Instituto Nacional de Antropología e Historia, tomo VI, núm. 34, México, D. F., pp. 79-110.

1973 El templo de las Inscripciones, Palenque. Instituto Nacional de Antropología e Historia. Colección Científica, Arqueología, 7. México, D. F.

SPINDEN, HERBERT J.

1924 The Reduction of Maya Dates. Papers of the Peabody Museum of American Archaeology and Ethnology. Harvard University, vol. VI, núm. 4. Cambridge.

1943 Ancient Civilizations of Mexico and Central America. American Museum of Natural History. Handbook Series, núm. 3, New York.

THOMPSON, ERIC

1932 "The Solar Year of the Mayas at Quirigua, Guatemala", Field Museum of Natural History. Pub. 315, Anthropological Series, vol. XVII, núm. 4, Chicago, pp. 392-403.

1950 Maya Hienoglypbic Writing: introduction, Carnegie Institution of Washington. Pub. 589. Washington, D. C. 
1952 "La Inscripción Jeroglífica del Tablero de El Palacio, Palenque", Anales del Instituto Nacional de Antropología e Historia, t. IV, núm. 32, México, D. F., pp. 61-68.

1959 Grandeza y Decadencia de los Mayas, Fondo de Cultura Económica, México, D. F.

1962 A Catalog of Maya Hieroglyphs, University of Oklahoma Press, Norman.

1970 Maya History and Religion, University of Oklahoma Press, Norman. 